\title{
EXPERIMENTAL RESEARCH INTO THE INFLUENCE OF PHOTODECTECTOR TYPES ON CHARACTERISTICS OF OPTICAL MINI-STICKS OF UNIFIED HUMAN- MACHINE INTERFACES
}

\author{
Sergei A. Golubin, Alexei N. Lomanov, Vladimir S. Nikitin, and Valery M. Komarov
}

Research, Development and Manufacturing Enterprise "TENSOSENSOR”

E-mail: 507z@mail.ru

\section{ABSTRACT}

The article provides the results of the experimental research into the influence of different types of photo detectors of digital optical mini-sticks on their transformation function - the useful mini-stick signal as a function of the mini-stick control lever deviation value. The set problem was solved using experimental research methods. Circuits with a photodiode (PIN photodiode PD1521B/TR8 manufactured by Everlight company) and circuits with a phototransistor (phototransistor KP2012P3C manufactured by Kingbright company) were studied. An automated test bench was used for the research. The test bench allows setting the mini-stick rotation angle and the value of mini-stick lever deviation from the central position to the left or to the right. The influence on mini-sticks was set by the test bench software. Based on the test results the test bench software plotted a ray path diagram. The mini-stick signal quality was assessed in terms of resolution, accuracy, non-linearity and hysteresis. The following results were obtained in the research. The mini-stick using a photo transistor as a photo detector ensures the output signal amplitude and resolution which exceed those of mini-stick with a photodiode by factor of 3.5 to 4 . It allows using mini-sticks with a phototransistor for high-precision control of complex robotic systems, manipulators and aircraft, and for designing joysticks and unified human-machine interfaces on their basis. The indices of precision, non-linearity and hystere-
\end{abstract}

sis of both mini-stick types are comparable and meet the basic requirements applied to control devices.

Thus, mini-sticks based on phototransistors can be regarded as the best in terms of the signal quality. Taking into consideration the circuitry, overall dimensions and the cost of hardware components which are identical for both photo detectors, mini-sticks based on phototransistors shall be considered to be more advanced switching devices.

Keywords: optical mini-stick, robotics control, switching device, elastic deformation polymer element, photodiode, phototransistor, experimental research

\section{INTRODUCTION}

Now the robotization is gradually approaching the stage where robotic systems consisting of numerous diverse robots remotely controlled by operators are applied. An example is a robotic system for forest fire extinguishing developed by Research, Development and Manufacturing enterprise "Tensosensor" LLC [1]. It contains three different specialized ground robots and a drone for aircraft reconnaissance. Compact, multi-purpose and unified input devices are necessary for efficient control of robots of such systems. Digital optical mini-sticks meet such requirements. A mini-stick is a two-coordinate mini-joystick, which is operated using a hand finger or thumb. Finger movement is 5 to 7 faster than hand movement, which allows performing control actions much quicker. Small size of mini-sticks 


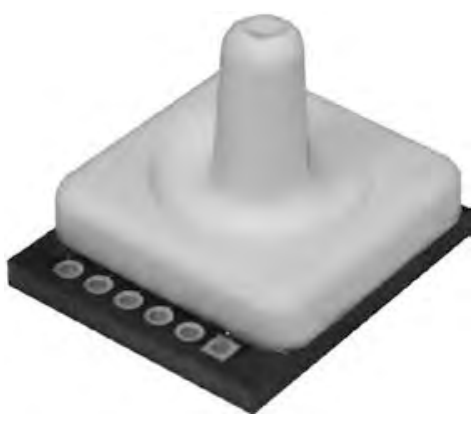

Fig. 1. Appearance of optical mini-stick

allows deploying several of them on the panel or control lever.

Research, Development and Manufacturing enterprise "Tensosensor" LLC in cooperation with Rybinsk P.A. Solovyov State Aviation Technical University has developed the design of the optical mini-stick considered in [2-7] and detailed in patent [10]. As compared with their equivalents, the optical mini-sticks feature design simplicity, constructability and high reliability. They are low-noise, fireand explosion safe, injury free, lightweight and multi-purpose due to reprogram ability of executed functions [11, 12].

The appearance of the optical mini-stick is shown in Fig. 1.

The optical mini-stick consists of printed circuit board 1 and elastic deformation element 2. Control lever 3 is located on elastic deformation element 2. The elastic deformation element made of an elastic polymer contains light-reflective surface 4 facing printed circuit board 1 . Photo detector 5 and several light sources 6 are installed on circuit board 1 . They are connected to the control microprocessor and face light-reflective surface 4, Fig.2.

The optical mini-stick operating principle is based on the effect of light reflection from the light-reflective surface of the elastic deformation element. When the control lever is pressed, the light-reflective surface is deformed depending on the press direction and magnitude. The light-reflective surface deformation changes the reflected light distribution, which is detected by photoelectric transducers. Based on readings of photoelectric transducers, the mini-stick microprocessor calculates the current position of the control lever.

Since the photoelectric transducer type influences the mini-stick performance greatly, it was very important to determine the influence of different photo detector type on the optical mini-stick characteristics.

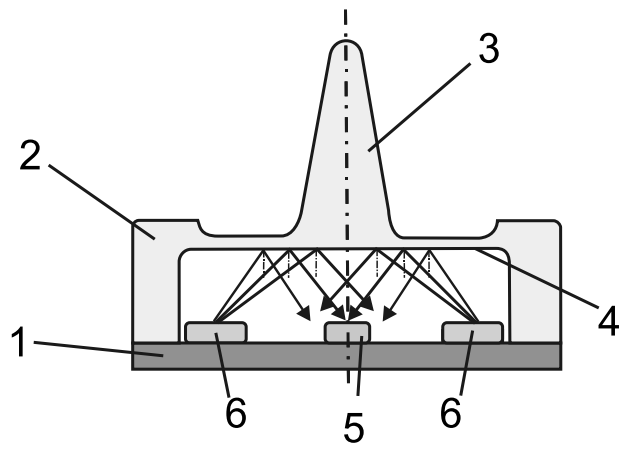

Fig, 2. Optical mini-stick: 1 - printed circuit board; 2 - elastic deformation element; 3 - control lever; 4 light-reflective surface; 5 - photo detector; 6 - LED

\section{RESEARCH METHODS}

2.1. The scientific task of the research was determining the influence of a type of mini-stick photo detector on its transformation function - useful mini-stick signal as a function of mini-stick control lever deviation value.

The set problem was solved using experimental research methods.

The useful signal of the mini-stick is two numerical values which correspond to the values of mini-stick control lever deviation on $\mathrm{X}$ and $\mathrm{Y}$ coordinates. The unit of measurement of the output signal is the mini-stick control microcontroller ADC counts which correspond to the ratio of voltage on the photoelectric transducer to ADC reference voltage. The voltage on the photoelectric transducer is determined by the intensity of the reflected light impinging onto it which depends on the mini-stick control lever deviation value.

The experiment method was the method of logging readings along axes $\mathrm{X}$ and $\mathrm{Y}$ in the points with set value of deviation of the mini-stick control lever from the central position and the deviation direction, which is set by the mini-stick housing rotation angle.

The mini-stick transformation function was studied using a special test bench for automated research into the mini-stick characteristics. The test bench allowed setting the mini-stick rotation angle and the value of mini-stick lever deviation from the central position to the left or to the right. The influence on the mini-stick under study was set by the test bench software. The test bench is described in more detail in [3-4, 6-7, 9].

To ensure the adequacy of the experiment for study of the influence of the photo detector type on the mini-stick readings the experimental spec- 
imens were manufactured with other general parameters:

- Elastic deformation element - with identical dimensions and shape;

- Light emitter type - infrared light emitting diodes KP-3216F3C manufactured by Kingbright company;

- Measurement device type - 10-digit analogdigital converter integrated into microcontroller PIC16F1704-I/ML manufactured by Microchip company.

The following devices were used as photoelectric transducers:

- In the circuit with a photodiode - PIN photo diode PD15-21B/TR8 manufactured by Everlight company;

- In the circuit with a photo transistor photo transistor KP2012P3C manufactured by Kingbright company.

The mini-stick readings were measured in the following conditions:

- Limits of deviation of the mini-stick lever from the centre: $-5 . .+5 \mathrm{~mm}$, with $0.5 \mathrm{~mm}$ pitch;

- Deviation direction: to the left (from $+5 \mathrm{~mm}$ to $-5 \mathrm{~mm}$ ), to the right (from $-5 \mathrm{~mm}$ to $+5 \mathrm{~mm}$ );

- Mini-stick rotation angle: from $0^{\circ}$ to $157.5^{\circ}$ with $22.5^{\circ}$ pitch;

- Number of reading measurements: 5 with subsequent averaging of the obtained values.

Based on the test results the test bench software plotted a ray path diagram. In the ray path diagram the useful mini-stick signal measurement results are represented as points with coordinates $X$ and $Y$, corresponding to numerical values of the mini-stick output signal. The measurement results obtained during deviation of the lever are shown as the points shift, Fig. 3. The ray path diagram allows assessing the mini-stick output signal quality visually: signal amplitude, resolution, precision, non-linearity, hysteresis.

The quality of the useful mini-stick signal was assessed based on the following indices:

1. Resolution is the parameter characterizing the mini-stick sensitivity;

2. Precision is the parameter characterizing the spread of values of the useful signal at a particular lever deviation;

3. Non-linearity is the parameter characterizing the transfer function curve deviation of the mini-stick under study from the straight line;
4. Hysteresis is the parameter characterizing the difference of the output signal values at identical value of the lever deviation but different directions of the signal change.

Resolution is the change of the number of the useful signal values per unit lever deviation magnitude. The resolution determines the mini-stick sensitivity, the higher resolution allows determining the mini-stick control lever position more precisely.

The mini-stick resolution is determined using the formula

$$
R=|\Delta x / \Delta L|,
$$

where $R$ is the mini-stick resolution, $\Delta L$ is the mini-stick lever deviation value change pitch, $\Delta x$ is the value of change of mini-stick readings at change of mini-stick lever deviation value by $\Delta L$.

To assess the precision of the readings, the value of root mean square deviation of measured values from the measured readings in the point with the set lever deviation was used. Relative value $\delta$ was calculated using the formula

$$
\delta=|R M S / \Delta X|,
$$

where $\delta$ is the relative deviation of mini-stick readings on the set coordinate, $R M S$ is the root mean square deviation of the mini-stick readings on the set coordinate, $\Delta X$ is the value range (amplitude) of the transfer function on the particular coordinate.

To assess non-linearity using the least-squares method, $X=k x+b$ approximating function was plotted for the straight line. Then non-linearity $N_{L}$ was calculated using the formula

$$
N_{L}=|X-X c a l c| / \Delta X \text {, }
$$

where $X$ is the actual value of the mini-stick readings for the particular coordinate in the particular point; Xcalc is the value calculated using the approximating function; $\Delta X$ is the value range (amplitude) of the transfer function for the particular coordinate.

Hysteresis of readings $G$ is assessed using the formula:

$$
G=|X r-X l| / \Delta X,
$$

where $X_{r}$ is the value of the mini-stick readings for the particular coordinate in the particular point 

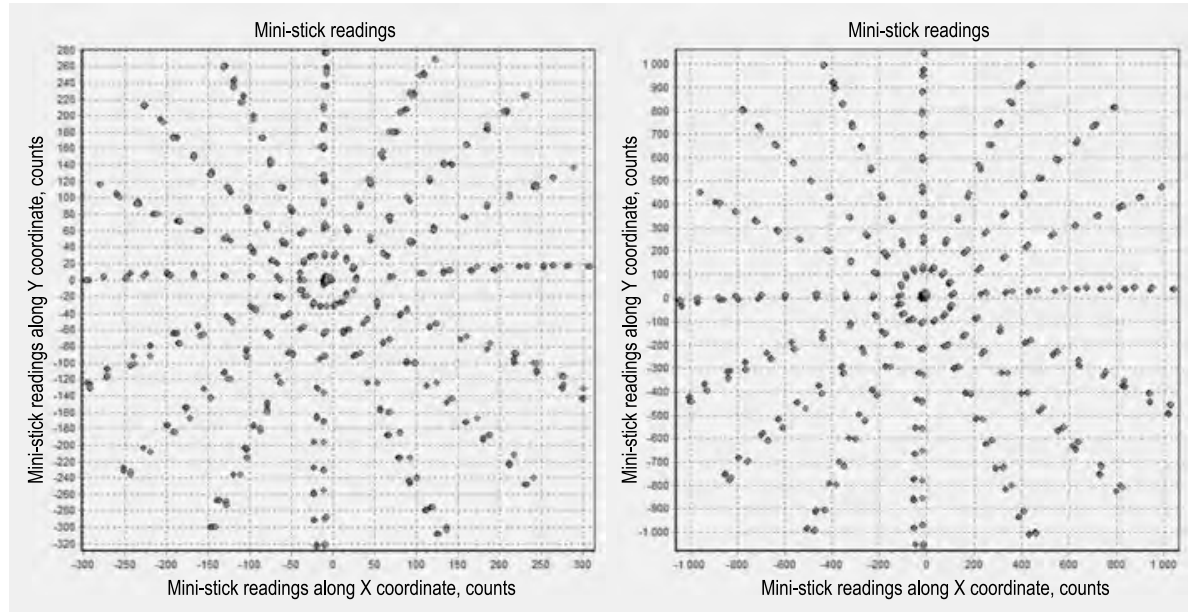

Fig. 3. Ray path diagrams of mini-stick readings

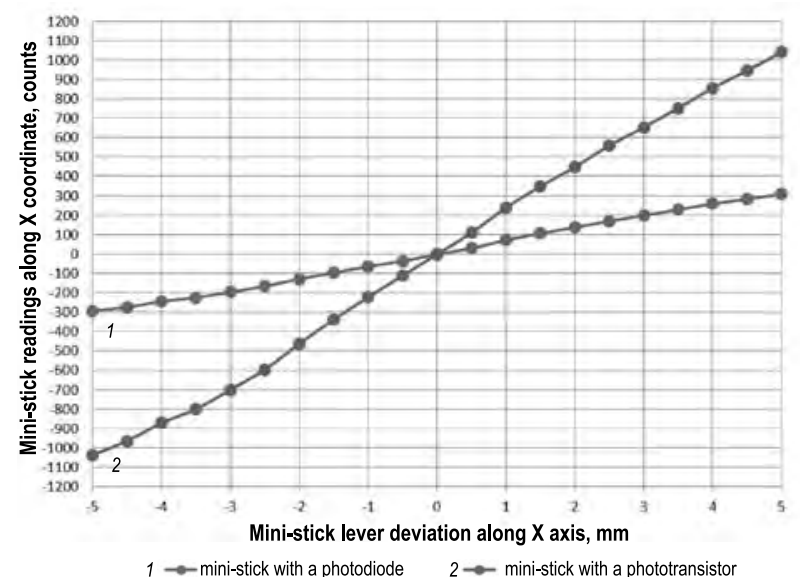

Fig. 4. Transformation function of mini-sticks of different circuits on coordinate $X$ (at $0^{\circ}$ mini-stick rotation angle)

when the lever moves to the right; $X l$ - for movement to the left; $\Delta X$ is the value range (amplitude) of the transfer function for the particular coordinate.

\section{EXPERIMENTAL RESEARCH RESULTS}

Ray path diagrams of the studied mini-sticks are shown in Fig. 3.

Graphs of mini-stick transformation function along $X$ axis (rotation angle $0^{\circ}$ ) are shown in Fig.4. Graphs of mini-stick transformation function along $Y$ axis (rotation angle $90^{\circ}$ ) are shown in Fig. 5.

To make it possible to compare, graphs of functions of different mini-sticks are superimposed on each other.

The calculation results are provided in Table 1.

\section{CONCLUSIONS AND RECOMMENDATION}

1. The selected circuits of mini-sticks on the basis of elastic deformation element, infrared chip LEDs and photodetectors on the basis of a photodiode and a photoresistor allow creating operable devices ensuring acceptable performance for their use in controls. The use of the mini-stick output signal in controls does not require any mathematically complex and resource-hungry processing, which simplifies the implementation and increases the response rate.

2. The mini-stick using a phototransistor as a photo detector ensures the output signal amplitude and resolution which exceed those of mini-stick with a photodiode by factor of 3.5 to 4 . The minimum resolution of a mini-stick with a phototransistor is much more than 100 counts per millimetre, which is much greater that all existing equivalents and it ensures the guaranteed mini-stick sensitivity of $0.01 \mathrm{~mm}$. It allows using mini-sticks with a phototransistor for high-precision control of complex robotic systems, manipulators and aircraft, and for designing joysticks and unified human-machine interfaces on their basis.

3. The indices of precision, non-linearity and hysteresis of both mini-stick types are comparable and meet the basic requirements applied to control devices. The mini-sticks based on phototransistors ensure several times as large indices.

4. A traditionally recognized drawback of phototransistors as compared with photo diodes is lower speed of the former. Build-up time and fall time for the phototransistors used in the experiment 
Table 1. Parameters of Mini-stick Signal Quality

\begin{tabular}{|l|c|c|}
\hline \multicolumn{1}{|c|}{ Mini-stick photodetector type } & $\begin{array}{c}\text { Mini-stick } \\
\text { with a photodiode }\end{array}$ & $\begin{array}{c}\text { Mini-stick } \\
\text { with a photoresistor }\end{array}$ \\
\hline Value range (amplitude) along X axis, counts & 602 & 2078 \\
\hline Value range (amplitude) along Y axis, counts & 599 & 2106 \\
\hline Min. resolution along X axis, counts/mm & 37 & 142 \\
\hline Min. resolution along Y axis, counts/mm & 39 & 162 \\
\hline Max. spread of values & $<0.5 \%$ & $<0.5 \%$ \\
\hline Max. non-linearity along X axis & $3.24 \%$ & $2.58 \%$ \\
\hline Max. non-linearity along Y axis & $4.25 \%$ & $2.64 \%$ \\
\hline Max. hysteresis along X axis & $1.83 \%$ & $2.02 \%$ \\
\hline Max. hysteresis along Y axis & $2.34 \%$ & $1.66 \%$ \\
\hline
\end{tabular}

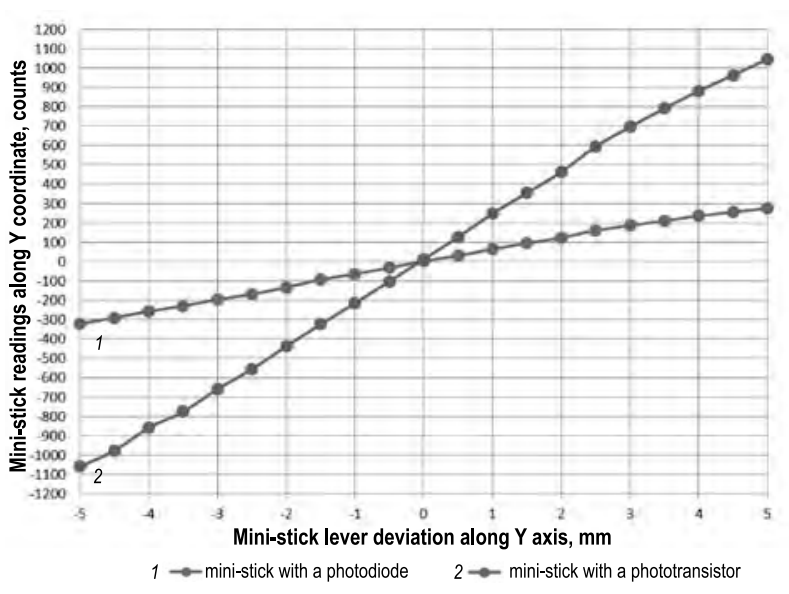

Fig. 5. Transformation function of mini-sticks of different circuits on coordinate $Y$ (at $90^{\circ}$ mini-stick rotation angle)

is no more than 15 microseconds. However, the human response time is on average no less than 100 milliseconds, which is 6.6 thousand times as longer, and for use in mini-sticks the delay ion phototransistor operation is negligible.

Thus, mini-sticks based on phototransistor can be regarded as the best in terms of the signal quality. Taking into consideration the circuitry, overall dimensions and the cost of hardware components which are identical for both photodetectors, mini-sticks based on phototransistors shall be considered to be more advanced switching devices.

\section{ACKNOWLEDGEMENTS}

The research works are conducted with financial support of the government represented by the Ministry of Education and Science of the Russian
Federation within the framework of fulfillment of the Agreement dated the $26^{\text {th }}$ of September, 2017 No. 14.579.21.0151. Unique identifier of applied scientific researches and experimental developments RFMEFI57917X0151. The authors are grateful to monitors and experts of Scientific and Engineering Enterprise Directorate for correct and well-wishing discussion of the obtained results.

\section{REFERENCES}

1. Nikitin V. S., Belov R.B., Robotic System For Forest Fire Extinguishing, Research, Development and Manufacturing enterprise "Tensosensor" LLC, MATERIALS OF THE XIII INTERNATIONAL SCIENTIFIC AND PRACTICAL CONFERENCE, October 30 - November 7, 2017, p. 24 Robotics, http://www.rusnauka.com/ books/2017-10-28-A4-tom-3.pdf.

2. Golubin S. A., Lomanov A.N., Nikitin V.S., Komarov V.M., Semenov E.I. Experimental research into characteristics of optical mini-sticks // Svetotekhnika, 2016, No. 6, pp. 17-20.

3. Golubin S. A., Lomanov A.N., Nikitin V.S., Komarov V.M., Semenov E.I. Research into the influence of the lighting circuit of optical mini-sticks on their characteristics // Svetotekhnika, 2016, No. 6, pp. 34-38.

4. Golubin S. A., Lomanov A.N., Nikitin V.S., Komarov V.M., Semenov E.I. Research into characteristics of optical mini-stick with VCSEL laser // Svetotekhnika, 2017, No. 1, pp. 24-27.

5. Golubin Sergei A., Lomanov Alexei N., Nikitin Vladimir S. and Komarov Valery M. Experimental research on the performance of optical mini-sticks with a common receiver // Light \& Engineering, 2015, Volume 23, Number 4, pp. 81-87. 
6. Golubin Sergei A., Lomanov Alexei N., Nikitin Vladimir S., Komarov Valery M., and Semenov Ernst I. Experimental study of how lighting patterns affect optical mini-sticks characteristics // Light \& Engineering, 2016, Volume 24, Number 4, pp. 105-110.

7. Golubin Sergei A., Lomanov Alexei N., Nikitin Vladimir S., Komarov Valery M., and Semenov Ernst I.. Study of Characteristics of VCSEL-based Optical Mini-sticks// Light \& Engineering, 2016, Volume 24, Number 4, pp. 111-116.

8. Golubin S. A., Nikitin V.S., Belov R.B. Digital optical mini-sticks for controlling robotic systems//Elektrosvyaz, 2015, No. 11.
9. Nikitin V. S., Belov R.B. Controlling without levers // Nauka i Zhizn, 2012, No. 12.

10. Optical mini-stick [Text]: patent No. 2594992, Russian Federation: MPK G06F 3/033/ Nikitin V.S. (RF), Pechyonkin A.A. (RF); applicant: Research, Development and Manufacturing enterprise "Tensosensor" Limited Liability Company (RU); appl. 26/01/2015; published on 10/08/2016, Bull. 22 (RF)).

11. A method of switching electric circuits and a polymorphic switch for its implementation: pat. No. 2455678, Russian Federation, No. 2011101226/08: appl. 13/01/2011: published 10/07/2012.
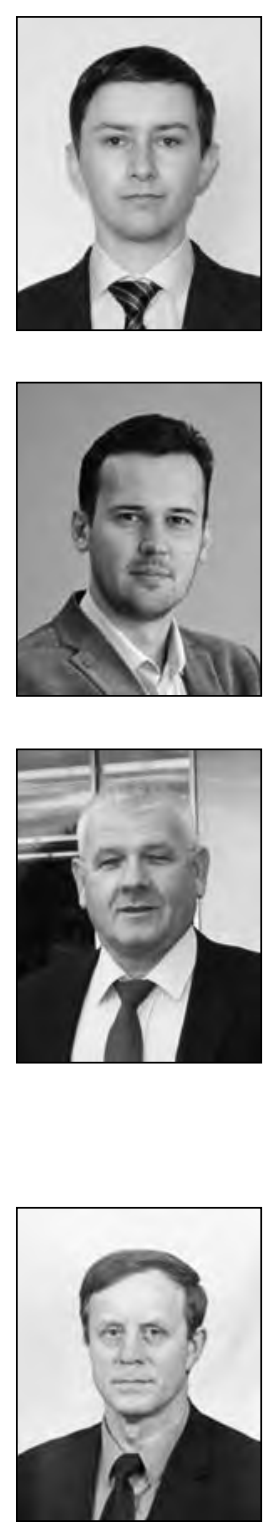

\section{Sergei A. Golubin,}

post-graduate of Federal State-Financed Educational Institution of Higher Professional Education «P.A. Solovyov Rybinsk State Aviation Technical University» (RSATU). He is graduated from RSATU in 2013. At present he is a systems engineer in Teuzosensor LLC

\section{Alexei N. Lomanov,}

$\mathrm{Ph} \mathrm{D}$. and associate professor in Federal State-Financed Educational Institution of Higher Professional Education (RSATU). He is graduated from Rybinsk State Aviation Technological Academy (now RSATU) in 2003. He has much experience in electrical engineering, microcontroller systems, industrial control and thin-film technologies, works in RSATU since 2003. At present, he is the dean of Faculty of radioelectronics and computer science

\section{Vladimir S. Nikitin,}

Ph.D. and CEO\&founder of Tenzosensor LLC. Inventor and idea man, leading expert in the field of R\&D organization and performance strategy development, organization of project team work. Miscellaneous expert in the field of physics, chemistry. electronics, material sciences, highly qualified designer and programmer, possesses a great experience of working at executive positions. He has 24 patents. 5 certificates for PC software products, $100+$ published works in scientific and popular editions; author of the book Technologies of the Future (Tekhnosfera publishing house, 2010)

\section{Valery M. Komarov,}

Ph.D. and Full Professor of Federal State-Financed Educational Institution of Higher Professional Education «P.A. Solovyov Rybinsk State Aviation Technical University» (RSATU). Graduated from Rybinsk Aviation Technological Institute (now RSATU) in 1972, got an academic degree in 1980. He has more than 40 years' experience in designing microprocessor systems and technological control systems. Works in RSATU from 1977.

He has 49 author's certificates. $6+$ published works 